\title{
CHARAUDEAU, P. Discurso político. São Paulo: Contexto, 2008. Tradução de Fabiana Komesu e Dílson Ferreira da Cruz.
}

\section{Resenhado por Geraldo Cordeiro Tupynambá ${ }^{1}$}

Em Discurso Político, Patrick Charaudeau propõe-se ao desafio de compreender o fenômeno político tomando o discurso como categoria central, sem, contudo, hipostasiar este conceito e convertê-lo em "um absoluto" do fenômeno político. Ao adotar a perspectiva interdisciplinar da Análise do Discurso (AD), Charaudeau - um "linguista do discurso" (p. 15), segundo suas palavras - dialoga com diversas disciplinas (psicologia social, ciências sociais, antropologia etc.) que contribuem para a caracterização dos contextos e das práticas sociais em que o discurso político se produz e opera. Entende que a linguagem é constitutiva da ação política, mas que esta não se resume àquela. Aproximando-se de Habermas, o Autor assinala que a linguagem exerce um papel mediador entre a instância cidadã e a instância política, contribuindo, assim, para assegurar a legitimidade da representação política. Isso não impede que ela seja instrumentalizada no exercício do poder político, por meio de regulamentação e de sanção.

Neste projeto, a AD não se dilui na Filosofia Política, na Ciência Política ou na História, uma vez que seu objeto de estudo não é a legitimidade da racionalidade política ou os mecanismos que conformam os comportamentos políticos, mas os discursos que embasam e tornam possíveis essa racionalidade e esses comportamentos (p. 37). Ainda que se conceba a política e a realidade do poder como, essencialmente, uma questão de ação, essa só pode ser levada a cabo se houver um discurso que a motive e que lhe atribua sentido.

1 Diplomata do Ministério de Relações Exteriores do Brasil (Itamaraty) e Mestrando junto ao Programa de Pós-Graduação em Linguística da UnB. 
Charaudeau descreve os lugares de fabricação do discurso político, ressaltando que o caráter político de um discurso reside menos em seu conteúdo do que nas condições criadas pela situação de comunicação. O discurso político não está reservado aos governantes ou aspirantes a governantes, nem aos pensadores da política; seu sentido se produz em função da interação e das identidades que dela participam. O Autor distingue três lugares de fabricação desse discurso: o da elaboração de sistemas de pensamento; o dos atos de comunicação entre atores da cena política; e, finalmente, o lugar onde se produz o comentário, em princípio alheio ao campo da ação política. Tais lugares não são estanques. Os discursos políticos, como os de qualquer outra formação discursiva, circulam no interior dos grupos que os constituem e entre diferentes grupos sociais e, ao se difundirem, se transformam.

Situado no encontro entre o julgamento - "a palavra que deve fundar a política" - e a ação - aquela que "deve gerir a política" - o discurso político parece estar, hoje em dia, em um processo de mutação, que tem levado o jogo político a abandonar progressivamente o terreno dos sistemas de pensamento e das ideologias (o "lugar do teor dos argumentos"), para concentrar-se mais na encenação dos embates políticos. Este movimento estaria sendo acompanhado, de forma análoga, pelos estudos sobre o discurso político, menos interessados, atualmente, nos "conteúdos" do discurso do que nos mecanismos de comunicação. Na visão de Charaudeau, os dois modos de abordagem do discurso político são indissociáveis.

Tendo circunscrito, na primeira parte do livro, a noção de discurso político, Charaudeau analisa, nas três partes seguintes, seus componentes essenciais: os contratos e estratégias do discurso político; as imagens do atores políticos; e os "imaginários de verdade", noção que, segundo ele, abre perspectivas analíticas não alcançadas pela noção de ideologia.

Na segunda parte, o Autor trata, portanto, das condições do discurso político, partindo da descrição do contrato de comunicação que fundamenta 
o dispositivo de interação nesse âmbito. Este dispositivo estrutura-se não em função de indivíduos, mas de "entidades humanas", caracterizadas como instâncias que se definem de acordo com seus atributos identitários, os quais, por sua vez, determinam sua finalidade comunicacional ( $p$. 55). Aos três lugares de fabricação do discurso político - lugares de governança, de opinião e de mediação -, corresponderão a instância política, a instância cidadã e a instância midiática. O papel dessa última é ambíguo, na medida em que seus integrantes, legitimados de antemão como informantes, buscam também - e precipuamente - a captação de novos adeptos, em razão das condições do mercado de comunicações. Assim, paralelamente ao dispositivo de exibição, que almeja a construção da credibilidade, opera o dispositivo de espetáculo, que visa à cooptação e que pode acabar constituindo a vocação preponderante da mídia (p. 63).

No âmbito da política, a identidade dos sujeitos constrói-se com base em sua legitimidade, em sua capacidade de atuar na esfera pública de maneira fundamentada, o que não invalida a construção discursiva da identidade, por meio do que se diz. Ambas as dimensões da identidade se interpelam e essa figuração dupla constitui elemento de tensão no discurso político. A construção da imagem - essencial na política contemporânea - tende a sobrepujar o conteúdo programático dos pronunciamentos políticos e ganha especial importância no estudo das estratégias do discurso político. Sendo o poder político fruto de uma delegação, de uma legitimidade adquirida e atribuída (p. 79), o sujeito político deve persuadir os indivíduos acerca dos valores que defende e construir para si uma dupla identidade discursiva, que articule teoria e prática, posicionamento ideológico e estratégia de gestão do poder. A persuasão - vista desde a Antiguidade como combinação de fatores racionais e emocionais - não se separa nitidamente, no discurso político, da convicção.

As estratégias discursivas do político dependem de fatores como a sua identidade, sua percepção da opinião pública e a posição de outros atores, aliados ou adversários. A encenação do discurso político oscila entre razão e paixão, misturando logos, pathos e ethos. As estratégias de 
persuasão compreendem, entre outros aspectos, as escolhas dos valores, as diferentes maneiras de apresentá-los e de argumentar, a "dramatização do discurso" e a construção da imagem de si (ethos).

$\mathrm{Na}$ terceira parte do livro, dedicada à imagem dos atores políticos, o último elemento da tríade retórica aristotélica constituirá o tema central. No contexto midiático atual, o ethos - a imagem de si projetada no discurso - está em constante reformulação. O ethos produz-se na dialética entre a identidade social e a identidade discursiva: "O ethos relaciona-se ao cruzamento de olhares: olhar do outro sobre aquele que fala, olhar daquele que fala sobre a maneira como ele pensa que o outro o vê” (p. 115). Por transparecer mais do que aparecer, o ethos não se constrói por marcas específicas. Ainda assim, o Autor elenca uma série de procedimentos linguísticos que propiciam sua elaboração. A forma de encadear as ideias e o conteúdo do discurso são elementos constitutivos da imagem do orador, mas esta não se produz apenas pelas palavras. Charaudeau incorpora à sua análise a figura física do orador, o sujeito falante empírico, sua voz, sua entonação, sua gestualidade, aproximandose, assim, de uma semiótica multimodal do ethos político.

É extensa a relação das virtudes que os atores políticos procuram amalgamar a seu discurso, a começar pela credibilidade. $\mathrm{Na}$ seção mais analítica do livro, Charaudeau propõe um inventário parcial das estratégias vinculadas a tais virtudes e descreve mecanismos de preservação da imagem, quando esta é atacada por denúncias de culpa ou responsabilidade. A taxonomia proposta por Charaudeau não resvala para a estereotipia de papéis, uma vez que a cada ethos correspondem limites, além dos quais eles deixam de ser funcionais. Assim, o excesso do ethos de "sério" sugere austeridade; o limite do ethos de compaixão é a aparência de fraqueza; e o risco inerente ao ethos de "culto" é a suposição de frivolidade.

Na quarta parte de sua obra, Charaudeau discute o "propósito" - tradução que abarca apenas parte das acepções, e talvez não as mais relevantes, do termo francês propos - do discurso político, isto é, a visão de mundo construída nessa formação discursiva, sua potencialidade 
cognitiva e os julgamentos que propicia. Considerando a amplidão do tema - a organização da vida em sociedade e o governo da coisa pública (p.189) -, objeto de diversas disciplinas e tendências teórias, Charaudeau recapitula a proliferação de noções formuladas pelo pensamento social para dar conta do "conteúdo" do discurso político (teorias, doutrinas, ideologias), criticando especificamente a noção de ideologia. Propõe uma revisão dos conceitos de representações sociais, da Psicologia Social, e de imaginário social, desenvolvido por Castoriadis, com vistas a formular a noção de imaginário sociodiscursivo, que integra o conceito de imaginário social ao quadro teórico da Análise do Discurso.

Segundo Castoriadis, o imaginário social é um universo de significações - nem verdadeiras nem falsas, mas verossímeis - com papel de fundador da identidade de um grupo e de fator de coesão social. É um "imaginário de verdade, que essencializa a percepção do mundo em um saber (provisoriamente) absoluto” (p. 205). Ao agregar o epíteto discursivo ao conceito de Castoriadis, Charaudeau implica que, para funcionar como espelho identitário, esse imaginário deve objetivar-se em uma racionalização discursiva. Tais imaginários circulam em um espaço de interdiscursividade e dão um testemunho das identidades coletivas e da percepção e dos julgamentos que os grupos fazem dos fatos sociais.

O potencial analítico da noção de imaginário sociodiscursivo é posto à prova na discussão dos imaginários de "tradição", de "modernidade" e de "soberania popular". Esses imaginários materializam conjuntos de valores, produzem sentidos e constituem identidades. Os diferentes discursos políticos buscam neles sua força de identificação e de persuasão, muitas vezes contraditória, para formular distintas estratégias e ethé particulares.

A parte final do livro discute a propalada tese da degenerescência do discurso político, segundo a qual o efetivo debate de ideias teria sucumbido diante da profusão de imagens. O ímpeto de transformação da sociedade, com base em projetos consensuados pela coletividade, teria dado lugar a slogans elaborados por especialistas em marketing, com vistas ao interesse imediato dos políticos. Em seu conjunto, a 
atividade política teria sido capitaneada pelos meios de comunicação. Sem aceitar integralmente ou renegar esse diagnóstico, Charaudeau considera que esse processo talvez represente a forma específica que o fazer político adquiriu em nossos dias. Como, na modernidade tardia, os grandes discursos redentores se provaram ineficazes, e como o auditório do discurso político se tornou mais heterogêneo, em razão do desaparecimento das massas, o discurso político tornou-se mais genérico e amorfo.

O Autor propõe, enfim, uma nova ética política. Ciente da importância da imagem na política, Charaudeau entende que as "máscaras do poder" - expressão que constitui o subtítulo da obra na edição original francesa - não devam ser encaradas necessariamente como artifícios para ocultar intuitos escusos, a serem desvelados pela análise. As máscaras devem ser consideradas, como no teatro, símbolos, que tornam a trama inteligível. Consistentemente com sua crítica à visão reducionista da ideologia como falsa consciência, Charaudeau vê na encenação do discurso político um aspecto constitutivo do fazer político, que deve ser bem compreendido para servir ao interesse coletivo.

Enviado em: novembro de 2009

Aprovado em: dezembro de 2009 gtupynamba@gmail.com, tupynamba@mre.gov.br 